\title{
Implementation of a Journal Prototype for Pregnant and Parenting Adolescents
}

\author{
Jennifer J. Bute, Assistant Professor ${ }^{\mathrm{a}}$ Corresponding Author \\ Karen Comer, Director ${ }^{\mathrm{b}}$ \\ Kathryn M. Lauten, Assistant Director ${ }^{c}$ \\ Helen Y. Sanematsu, Assistant Professor ${ }^{\mathrm{d}}$ \\ Courtney M. Moore, Communication Designer ${ }^{\mathrm{e}}$ \\ Dustin Lynch, Communication Designer ${ }^{\mathrm{e}}$ \\ Neale R. Chumbler, Professor and Department Head ${ }^{\mathrm{f}}$
}

${ }^{\mathrm{a}}$ Department of Communication Studies

IU School of Liberal Arts

Cavanaugh Hall 307J
Indiana University Purdue University Indianapolis
425 University Blvd
Indianapolis, IN 46202, USA
jjbute@iupui.edu
317-274-2090

${ }^{\mathrm{b}}$ Collaborative Research \& Health Geoinformatics

The Polis Center

1200 Waterway Boulevard

Indianapolis, IN 46202, USA

'Survey Research Center at IUPUI

Indiana University Purdue University Indianapolis

425 University Blvd, CA133

Indianapolis, IN 46202-5140, USA

${ }^{\mathrm{d}}$ Visual Communication Design

Herron School of Art and Design, Indiana University

735 W. New York St., Indianapolis IN 46202, USA

${ }^{\mathrm{e}}$ Attic Design Collective

212 W 10th Street Suite D385

Indianapolis, IN 46202, USA

${ }^{\mathrm{f}}$ Department of Health Policy and Management

College of Public Health

University of Georgia

110 E. Clayton Street, Ste. 300

Athens, GA 30602, USA

NOTICE: this is the author's accepted version. The final version was published as: Bute JJ, Comer K, Lauten KM, Sanematsu HY, Moore CM, Lynch D, et al. Implementation of a journal prototype for pregnant and parenting adolescents. Evaluation and Program Planning. 2014 Oct;46:122-30. Available from: http://dx.doi.org/10.1016/ j.evalprogplan.2014.05.009 
Journal Prototype for Pregnant and Parenting Adolescents 2

\begin{abstract}
Teenage pregnancy and childbearing remain pressing public health issues that have garnered attention from public health officials and social services agencies. This paper reports on the initial implementation and formative evaluation of a journaling program used as a means of communicating health information to pregnant and parenting adolescents (young women age 1519) while also providing participants with a means of self-expression. The journaling prototype was implemented in a community-based agency in the Midwest by Family Support Specialists (FSSs) who made home visits on a monthly basis to assist pregnant and parenting adolescents (n =52) with successful family planning and public health education. A mixed method approach of qualitative (analysis of journals, field notes, and responses of semi-structured interviews with
\end{abstract} FSSs) and quantitative (questionnaires from pregnant and parenting adolescent respondents) data with purposive sampling was employed to evaluate the implementation of the journaling intervention. Twenty of the 52 study participants were pregnant when the journaling intervention was implemented, while 32 were not pregnant, but recently had a child and were currently parenting. Two core themes emerged from analysis of the data after the implementation of the journals: 1) usefulness of the journal and responsiveness to participants' information needs 2) functionality challenges. The results offer practical starting points to tailor the implementation of journaling in other contexts. Further, areas for improvement emerged regarding the distribution timeline for the journal and the content of the journal itself. As such, we discuss the lessons learned through this collaborative project and suggest opportunities for future phases of the journal intervention.

Keywords: program evaluation, journaling, adolescent pregnancy 
Journal Prototype for Pregnant and Parenting Adolescents 3

Implementation of a Journal Prototype for Pregnant and Parenting Adolescents

Although teen birth rates have been on the decline for several decades (The National Campaign to Prevent Teen and Unplanned Pregnancy, 2010), adolescent pregnancy and childbearing is still a major concern for public health officials, sexual health educators, and social service agencies across the United States. In fact, the U.S. has one of the highest rates of teenage pregnancy among developed countries (Hamilton, \& Ventura, 2012). Children of adolescent parents are more likely to face barriers in accessing adequate health care resources and are at risk for a variety of health conditions that necessitate long term care, such as cerebral palsy, mental retardation, and respiratory problems (Martin, Hamilton, Ventura, Menacker, \& Kirmeyer, 2006). Teenage mothers must also adjust to the responsibilities and demands of parenting, often in the context of economic and social disadvantage, burdens leading to adverse mental outcomes. For example, adolescent mothers experience significantly higher rates of depression (both prenatally and postpartum), suicidal ideation, substance abuse, and posttraumatic stress disorder than adult mothers and their nonpregnant peers (Hodgkinson, Beers, Southammakosane \& Lewin, 2014).

In response to these concerns, a number of public health campaigns and interventions have been developed with the aim of reducing incidents of teenage pregnancy (e.g., Doniger, Adams, Utter, \& Riley, 2006; Pinkleton et al., 2008; Roberto, Zimmerman, Carlyle \& Abner, 2007). For example, interventions using computer and Internet-based programs have been successful in increasing adolescents' knowledge of the benefits of delayed sexual activity and improving their confidence in negotiating condom use with sexual partners (Roberto et al., 2008). Such education efforts are indicative of campaigns that combine a goal of deterring adolescent pregnancy with other health-related goals like encouraging safer sex practices and 
Journal Prototype for Pregnant and Parenting Adolescents 4

reducing rates of sexually-transmitted infections among teens. Yet practitioners and health officials must address not only the prevention of teen pregnancy, but also the health of teens who are already pregnant or parenting, and the well-being of their children. Addressing these needs also provides opportunities to gain a better understanding of the experiences and aspirations of teen parents as they experience this role in their lives. A considerable need exists to implement a tailored program that enables pregnant and parenting adolescents with the flexibility to express their perspectives, while at the same time promoting public health resources and services (Busum \& Mattke, 2013; de Meij et al., 2013).

To that end, the Maternal and Child Health Division (MCH) of the Indiana State Department of Health (ISDH) created The Pregnant and Parenting Adolescent Support Services (PPASS) program to promote the development of integrated systems of support services for pregnant and parenting adolescents and their families. Based on the most recent available data, the teen birth rate per 1,000 population in women ages 15-19 in Indiana was slightly higher than the national average (37.3 in Indiana, compared to 34.3 on average in the U.S.), and while the U.S. teen birth rate declined 17\% between 2007 and 2010, in Indiana it declined only 13\% (Hamilton \& Ventura, 2012). Via a 2010 internal survey of its agency partners, MCH identified a lack of community resources, family support barriers, and awareness of resources as the most significant challenges in the promotion of the health and well-being of pregnant and parenting adolescents. $\mathrm{MCH}$ then funded a series of research studies to evaluate various means for communicating health information to teens regarding pregnancy, prenatal care, and parenting. As part of this funded research series, we implemented a journal program for pregnant and parenting teens in a local context in order to perform a formative evaluation of this type of intervention. 
Journal Prototype for Pregnant and Parenting Adolescents 5

As part of this formative evaluation, we identified both facilitators and barriers related to the implementation of the journaling prototype for pregnant and parenting teens. Implementation, defined as a particular set of activities designed to put into practice a program of specific dimensions, is a complex enterprise (Fixsen et al., 2005). There are often disconnects in the process of developing a program or intervention, its evaluation, and its implementation in a real-world setting. Failure to evaluate implementation practices in early phases of a program can lead to participant disengagement, thwarting the potential public health impact of health behavior research (Greenhalgh, Robert, Macfarlane, Bate, \& Kyriakidou, 2004; Tse, Nansel, Weaver, Williams, Botello-Harbaum, in press). Kitson et al. (1998) indicated that the overall practice environment can influence the implementation of programs. How health-promotion programs in general, and journaling programs for pregnant and parenting adolescents in particular, operate under real-life conditions have rarely been evaluated (van Nasau et al., 2013). When programs are introduced under less controlled conditions, as similar to the present study, insight into factors influencing the implementation of these programs is crucial for translation into practice and systematic planning of dissemination strategies (van Nasau et al. 2013; Bartholomew et al. 2001). Consistent with the implementation science literature, we aimed to capture in-depth information on participant and contextual factors in a complex setting that facilitated or hindered successful implementation. Practitioners and scholars can then draw on these factors to enhance future implementation efforts to tailor programs and interventions to be more congruent with and accommodative the needs of the clients being served (Jolley, 2014; Stetler et al., 2006).

The following sections describe the implementation of the journal prototype, the context where the program was implemented, the results of the formative evaluation of the barriers and facilitators of the initial implementation, and the conclusions drawn about usefulness of the 
Journal Prototype for Pregnant and Parenting Adolescents 6

journal for future interventions. Qualitative and quantitative methods were used to evaluate the program as implemented.

\section{PROGRAM DEVELOPMENT AND IMPLEMENTATION}

The development and evaluation of the journal was carried out by a diverse, interdisciplinary team of researchers in the fields of Communication Studies, Sociology, Geoinformatics, and Visual Communication Design. The research team collaborated closely with an Indianapolis-based design company for journal design and development.

\section{Rationale for Selection of a Journal Modality}

During the first phase of this project, the researchers and designers conducted focus groups with pregnant and parenting adolescents to compare a variety of modalities for communicating health information related to the goals of the PPASS program (see Authors, in press for a complete description of the methods, analysis, and results of the focus group sessions). The modality options included a customizable journal, a mobile bus unit designed to travel to various locations, and an interactive kiosk. During the sessions, participants were able to test and compare the three prototypes and to ask questions of the design team who had created the three options (Authors, in press). Feedback from participants suggested a strong preference for the journal as a means of both conveying and gathering information. Participants were drawn to the journal as a way to gain information about pregnancy and parenting and as a mechanism for fostering self-expression. They were especially enthusiastic about the idea of other people reading their journals, including institutional representatives like social workers and even the researchers themselves. The participants articulated a strong desire for others to understand their point of view and wanted to reduce the social stigma surrounding teenage childbearing (Authors, in press). 
Moreover, personal writing and self-expression have a long history of use as tools for self-understanding and improvement, and research has pointed to the effects of writing in improving health and psychosocial well-being (Lepore and Smyth’s, 2002). One formative study examining the benefits of journaling found that students who wrote about traumatic events had fewer visits to the campus health services over the subsequent six months than those who did not write about such events (Pennebaker \& Beall, 1986). And Pennebaker and Seagel (1999) have argued that: "Extensive research has revealed that when people put their emotional upheavals into words, their physical and mental health improves markedly” (p. 1244). Long-term benefits of expressive writing include greater self-awareness and confidence, reduced stress and anxiety, improved mood, improved physical health, a better understanding of the life event, and the development of a conduit for improving communication with a counselor (Pennebaker \& Seagal, 1999; Baikie \& Wilhelm, 2005).

While we have not seen published studies on the benefits of self-expression with pregnant and parenting adolescents, several writing programs for adolescent mothers do exist. Two such programs of note are the Adolescent Mother Journaling Program through the University of Missouri and the Baby Basics Program through the What to Expect Foundation (e.g. Keeling \& Bermudez, 2006; Thomas et al, 2012.). These programs have incorporated forms of self-expression, but neither has published data related to the specific impact of the writing components of their projects. Based on the evidence cited here that written expression has benefits and the preference for journals expressed by participants in the focus group study, we set out to develop and implement a journal for pregnant and parenting teens (see Figure 1).

Journaling is an active learning technique that enhances self-examination (i.e., looking back at what has happened in an adolescent mother's life and gaining the perspective of others, 
Journal Prototype for Pregnant and Parenting Adolescents 8

all in an attempt to improve their own personal circumstances) (Blake, 2005). There have been at least 5 home visitation programs aimed at providing health care resources and modifying outcomes for pregnant and parenting adolescents (Atkinson \& Peden-McAlpine, 2013). The primary focus of these programs have centered on one-way communication (i.e., nurses supporting and disseminating public health information on adolescent maternal development). However, scant information exists on the perspective of the pregnant and parenting adolescent, focusing on their self-expression of their experience (see Atkinson \& Peden-McAlpine, 2013). To fill an important void in the literature, our journaling program has the flexibility of providing pregnant and parenting adolescents with the capacity to communicate their feelings and experiences in a format that can be expressive, while at the same time provide an opportunity for providers and clinicians to intervene and respond to unmet needs.

\section{Evaluation Setting and Community Partner}

Critical to the evaluation of the journal was securing a community-based agency for collaboration and implementation purposes. To that end, we identified a community implementation partner to recruit pregnant and parenting teen participants and implement the journaling program with those teens. The research team was fortunate to engage Empowering Teens as Parents (ETAP) as its community implementation partner. ETAP was developed by Mental Health America of Lake County, IN in collaboration with Early Learning Partnership of Northwest Indiana and with funding from ISDH, to bring parent education and support to over 150 pregnant and parenting teens in Lake County, IN. All participating families are assigned a Parent Educator (PE) and Family Support Specialist (FSS) to assist them in achieving educational goals, accessing successful family planning, and coordinating community supportive services. ETAP coordinates with local school systems to identify teens in need and also accepts 
outside referrals to serve families who are not in the partnering schools or not enrolled in school, including those who are over school age and/or already with a diploma or GED. Families get one visit a month from the PE and one visit a month from the FSS. Participation is completely voluntary, free, and open to any pregnant or parenting teen living in Lake County.

The five FSSs at ETAP along with their supervisor agreed to participate as project coinvestigators as part of the formative evaluation. Each participating ETAP staff member successfully completed online human subjects research training and a one-day training session conducted by the research team. This training included an introduction to the journal prototype, followed by a brief review of best practices for human subjects research, and instructions on journaling implementation and evaluation. The research team also developed a facilitator's manual for the ETAP to reference as needed. Finally, we held a follow-up training session via conference call one day before the start of participant recruitment to review the study protocol and provide an opportunity to ask questions and solve any outstanding issues for clarification.

\section{Journal Design and Content}

The journal was designed as a modular piece (see Figure 2); a binder that holds individual booklets that can be switched out easily. This design allowed the team to develop a total of six iterations, or inserts, of the journal over the course of the project, with each insert focusing on a different content area. The design firm used a variety of techniques to develop an identifiable brand, look, and feel for the journal. Drawing on research from the fields of design and psychology (e.g., Azoulay \& Kapferer, 2003), as well as the voices of participants in the focus group phase of the study, the design firm produced two brand tools used to guide all creative decisions regarding the journal. The first of these tools was a brand essence, which describes in simple terms what the journal should be to the participants: a needed friend. A 
needed friend was defined as someone who is genuine (e.g., authentic, honest, respectful), positive (e.g., supportive, encouraging, engaging), and reliable (e.g., informative, trustworthy, open). The second brand tool is a persona, which is a fictional person that embodies the brand essence. A written and visual representation of this person, who the design team referred to as “Tori” was created, telling and showing who she is, what she likes, and how she relates to the world. The brand essence and persona guided all creative decisions made for the journal. The first major decision was the name of the journal: For Real, which came directly from the need for the brand to be genuine. For Real is about being upfront and honest, and draws to mind something a friend might say. Thus, as the design team wrote the content of the journal, they adopted the tone of a genuine friend in giving advice, communicating health information, and soliciting thoughts from journal users. The brand essence and persona also guided other choices, such as the feel of the journal cover, the colors used for text and images, and the typography.

The journal sections in each insert consisted of five categories: quizzes, prompts, drawing exercises, guided journaling, and free journaling. Quizzes, modeled after the kind commonly found in teen magazines, allowed the team to gather quantifiable information, like how many of the participants have access to a smart phone, how often the service is interrupted, and so on. Specific prompts were designed to make it easier for the participants to begin writing, as they could start by answering a simple question (e.g., “What makes you feel safe?”). These journal pages allowed enough room for writing to make it clear that the participants were encouraged to write in depth about the topic. The prompts also served as a tool that the research team could use to gather qualitative information about specific topics, such as prenatal visits or family planning. Drawing exercises offered opportunities for participants to experiment with different forms of expression and cement their ownership of the journal. Guided journaling pages included a fill- 
in-the-blank style section where participants answer pointed questions meant to get them thinking about big picture concepts or to help guide participants through goal-setting exercises. Finally, free journaling sections always began with the prompt, "What’s on your mind?” followed by blank space for writing. The journal also included necessary study materials, such as the informed consent form, a planning calendar, and a variety of informational inserts related to parenting tips, contraceptive information, and health care resources.

The informational backbone of the journal was based on multiple sources, including the PPASS goals (see Table 1) and the ETAP curriculum used to educate families. The PPASS priorities guided the bulk of the journal content. In each of the six iterations of the journal, we emphasized one or two PPASS goals (e.g., smoking cessation and access to healthcare, or family planning and nutrition) and created 32 pages of content that addressed these goals specifically. For example, the first two inserts addressed PPASS priorities related to knowledge of appropriate parenting skills and reducing subsequent pregnancies. Accordingly, those inserts included a parenting quiz designed to test participants' knowledge of appropriate parenting skills, such as disciplinary techniques, as well as space for journal users to reflect on the joys and challenges of parenting. Regarding reduction of subsequent pregnancies, the inserts include prompts asking participants to write about if and when they wanted to have another child and what sort of contraception they currently used. These examples illustrate the interactive nature of the journaling tooling in encouraging self-expression and reflection while also providing the research team and ISDH with valuable information (e.g., the results of the parenting quiz, information about participants' use of contraception). Moreover, they illustrate the approach the team took in communicating information in creative and non-threatening ways. Rather than 
Journal Prototype for Pregnant and Parenting Adolescents 12

giving directives about parenting techniques, journal tools like the parenting quiz, allowed participants to explore and compare the pros and cons of different parenting styles.

The second major source of journal information was the ETAP team. We wanted to make sure the journals could be used as a tool to help, rather than hinder, the work of the FFSs and stay consistent with their existing curriculum. We consulted with them during the training session to determine what information would be most valuable for them to use and reviewed their curriculum when designing each iteration of the inserts to ensure that the journal contained accurate, up-to-date information.

The design firm was responsible for developing the content of the journal based on the various content sources. After each iteration of the journal was developed, the multi-disciplinary team checked it for accuracy, IRB compliance, and alignment with PPASS priorities. Each round of review yielded suggested changes in the content and layout of the journal. The suggested modifications were made to the journal, and journals were then distributed to ETAP for implementation by the FSSs. These FSSs delivered inserts every two weeks, with completed inserts exchanged for new inserts every two weeks.

\section{Field Implementation and Participant Enrollment}

Field implementation occurred over a three month period. At the first visit by FSSs with each of their adolescent clients, FSSs invited their clients to participate in the study. Because ETAP's client population consists primarily of young women, we recruited a female sample for purposes of the study. This recruitment process consisted of study personnel reading to them a recruitment script, which described the purpose of the study and what would be expected of them to participate. Each client who wished to continue provided their signature on an “Agreement to Participate” assent form that was developed with appropriate educational and maturity level for a 
15-year-old participant. A waiver of parental consent was approved by the Institutional Review Board. The newly consented study participants then completed a survey. All recruited participants received a \$25 gift card to a retail store after the enrollment process and an additional \$25 gift card upon completion of the study. Participants completed a second survey that assessed their perceptions of the journal at the end of the study.

Total targeted recruitment for the study was 60 participants. Within the first week, ETAP recruited 31 participants. An additional 21 participants were recruited the following week, for a total of 52 study participants enrolled. More teenage (15-17) participants (56\% or 29/52) enrolled than adult (18-19) participants (42\% or 22 /52). While Hispanic individuals made up the largest portion of our enrolled participants ( $40 \%$ or $21 / 52)$, there was also a large portion of non-Hispanic white (25\% or 13/52) and non-Hispanic black (33\% or 17/52) enrollees. Most enrollees were already parents (62\% or 32/52). Just one of the pregnant participants was already a parent. Most of the enrollees were students (67\%, or 35/52). Twenty-five percent (25\% or 13/52) of the enrollees held jobs (either part-time or full-time). The primary source of income for most enrollees was their parents (67\% or 35/52). Seventeen percent (17\% or 9/52) reported employment as being their primary source of income and 13\% (or 7/52) reported public assistance as being their primary source.

Of the 52 participants, 38\% (or 20/52) were pregnant (i.e., “pregnant participants”) at the time they started the journal program, and the rest were already parenting (i.e., "parenting participants”). Of the pregnant participants, over half (55\% or 11/20) were in their third trimester at the beginning of the study, and some of them gave birth over the course of the journal intervention. All of the pregnant participants (100\% or $20 / 20)$ reported that they were 
Journal Prototype for Pregnant and Parenting Adolescents 14

currently seeing a health care provider for prenatal care, and all of them described their current pregnancy as unplanned.

During the course of the project, journal inserts were distributed for June, July, and August, with the journal binder and the first journal insert distributed at the enrollment visit. Upon delivery of journal inserts, the FSSs discussed existing journal content along with any newly added topics, questions, information, or suggestions. Completed journal inserts were collected for a six-week period in order to allow time for data entry and analysis prior to the submission of our final report to ISDH. Two weeks after the first journal distribution and every Friday during the project period thereafer, ETAP shipped all completed and collected journals back to the research team for scanning, data entry, and analysis. Once facilitation visits were completed, facilitators contacted each participant individually to provide one last formal opportunity for each to remove any verbal data from material for public presentation.

\section{Evaluation Design and Data Collection}

In order to evaluate the potential of the journaling program, several means of data collection were used. We used a survey to gather demographic information about study participants about the beginning of the study and a second survey to assess their perceptions of the journal at the end of the study. In addition to the survey, the journals themselves were also a primary source of data about and from the participants and provided a means of analyzing trends in journal use and completion over the course of the project.

Data were also collected via the FSSs. During the pre-implementation phase, the FSSs were trained as co-investigators and participant observers. Each time they collected a completed journal insert, the FSSs wrote a facilitator report worksheet. These reports included a space for field notes and prompted the facilitators to make specific observations and to ask certain 
Journal Prototype for Pregnant and Parenting Adolescents 15

questions about participant use of the journal. The FFSs reports of what they observed in the field were quite candid and included both positive and negative evaluations of the journal.

After completion of journal implementation, we also scheduled a debriefing call with ETAP staff (the FSSs and their immediate supervisor) to gather their opinions regarding the study, their experience as facilitators, impressions of any general themes participants shared in common, and recommendations for future implementations of the journal project. Again, we found their comments to be quite candid. For instance, they were not afraid to express in detail the challenges they faced in putting the journal program into practice. The information gathered in this session assisted in an assessment of the program's functionality.

\section{Qualitative Analysis of Journals and Facilitator Report Worksheets}

As the research team received completed journals from ETAP, we scanned the journals and created electronic pdf files. We posted those files to a secure server so that all members of the research team had access to the journals. Two analysts on the team with expertise in interpreting qualitative data read all 123 completed journals. The analysts identified recurring themes (Owen, 1984) across the journals, paying special attention to comments related to PPASS priorities $^{1}$. A third analyst with expertise in issues of design and functionality read both a subset of the completed journals and a subset of the 175 facilitator report worksheets. The analyst read the comments and notes on 100 of the worksheets and a sample of completed journals to determine participants’ perceptions of the journal's likability, usefulness, and convenience. Thirty-six journals were reviewed, with this sample consisting of 12 journals from each journal round (Part 1, Part 2, Part 3) selected at random. The analyst read these 36 journals to determine

\footnotetext{
${ }^{1}$ The thematic data relating to PPASS priorities are reported elsewhere.
} 
their level of completeness and the engagement of the participants, as well as to assess those sections of the journal that tended to be more popular with participants.

\section{RESULTS OF THE PROGRAM EVALUATION}

The results of the program evaluation centered on two primary themes: 1) journal usefulness and perceived responsive to participants’ information needs and 2) functionality challenges. We elaborate on each of these themes in the following section.

\section{Journal Usefulness and Responsiveness to Participants' Information Needs}

To understand whether participants found the journal content useful and responsive to their needs, we used survey data, FSSs worksheets, and debriefing calls with the ETAP staff to gauge participants’ perceptions of and reactions to the journal.

Responses to follow-up survey questions revealed how interesting and useful participants found the journals. The free writing portions of the journals were reported as being the most interesting and useful, followed by pregnancy and parenting tips. Eighty-two percent (82\% or 36/44) agreed or strongly agreed that the journal was interesting, 73\% (or 32/44) agreed or strongly agreed that the journal was “cool”. Sixty-eight percent (68\% or 30/44) agreed or strongly agreed that they used the journal when they were bored and 93\% (or 41/44) agreed or strongly agreed that writing in the journal helped them express their feelings about pregnancy or parenting. Eighty-four percent (84\% or 37/44) would recommend the journal program to a friend and 66\% think the journal can help them become a better parent. Most (93\% or 41/44) responded that the journal program can help teens learn important information about having a healthy pregnancy. Forty-two percent (42\% or 19/45) of the respondents reported using the calendar on at least a weekly basis. Participants who shared their journals with another person 
most frequently indicated parents amongst those with whom they shared their journals, although $38 \%$ (or 17/45) reported never sharing their journals.

In addition to using data from the survey, we also used the worksheets completed by the FSSs to draw conclusions about the likeability and usefulness of the journals. Based on reports from the FSSs, many participants stated during their interactions that they liked the journal and were enthusiastic, and even emotional, when offered the opportunity to take part in the journaling project. For instance, one FSS wrote:

Participant started to cry when she got the journal in her hand. She stated that it will be nice to have a place to put all of her thoughts and feelings down... She was excited about the planner because she wants to try to organize herself more and she thinks she can use the planner. She was excited to begin writing in the journal as soon as she could. In addition to expressing that they liked the journal, participants also commented to the FSSs about whether they perceived the journal as useful. Many participants valued the journal because it helped them express themselves: "The participant said the journal helped her because she has a way to 'talk' about what's on her mind when she has nobody to go to.” Other participants noted that the prompts were interesting and that the journal helped them think about their future and discover the joy of writing. For instance, one FSS wrote:

The participant said the journal made her think about things she never considered and it made her think of her future. The participant was excited that the new insert is focused on her child. The participant realized that she enjoys writing more than she realized.

Other FSS's commented on their clients learning helpful information about pregnancy, parenting, and health “The participant said she liked how it made her think about things like her 
health and the future.” Still others were able to use the journal as an escape: “Client stated her journal helped her escape the negativity that's been going on at home.”

Although many participants expressed enthusiasm for the journal, our interview with the FSSs also indicated some problems with the journal content. One major concern centered on tailoring the journal content to the specific needs of participants. For instance, young women who were pregnant at the time of the journal intervention told the FSSs that they did not find the parenting sections relevant to them. Although the team and ETAP thought these sections would be helpful to those preparing for parenthood, some pregnant participants skipped these portions of the journal. The ETAP staff also mentioned that some participants seemed to get bored with the journal over time and thought that greater customization of the content might alleviate fatigue with using the journal. This dropoff in journal use is supported by the decline in journal completion detailed in the next section.

\section{Functionality Challenges}

Functionality challenges revealed by the data suggest that journal use and completion, in terms of both overall journal completion and completion of particular sections, declined over time. We also found that the timing of the implementation made the program difficult for our community partners.

Trends in Journal Completion Forty-nine (49) of the first journal inserts were completed and returned. There was a decrease in journal completion over the course of the six-week data collection period, with forty-one (41) of the second journal inserts returned and only thirty-three (33) of the third journal inserts returned. While the number of parenting participants completing journals dropped off between Part 1 and Part 2 journals, with eight (8) fewer parenting participants completing the latter, all of the pregnant participants who returned the first journal 
also returned the second. A similar number of participants in each race/ethnicity group dropped out of journal completion between the first and last journal insert, with a drop of six (6) Hispanic participants, a drop of four (4) black participants (25\%), and a drop of five (5) white participants. In addition to overall trends in completion and return of the journal inserts we also rated the level of engagement that participants had with their journals and the completeness of specific sections in the journal. For Part 1, it was noted that some of the journals that were the least filled out also had the lengthiest free-writing sections. This might indicate that those with the least time or interest in the journals find them most useful or interesting as a place to express themselves in unstructured ways. Journals that demonstrated an overall higher degree of use with a varying degree of quality seemed to prefer prompted sections that included listing “20 Things I Can’t Stand” and dismissed or write rote responses for a section called “I Feel Strong When” (see Figure 3 for a good example of one of these completed sections). These patterns could indicate a more goal-oriented approach to the journals, in which they are not seen as an opportunity for meaningful expression or reflection (“I Feel Strong When”) but more as a task to be accomplished (the less reflective “20 Things I Can’t Stand”). For Part 2, there were mostly brief responses in most sections of the journal. In terms of quality of engagement, at least half showed some indication of reflection (e.g., expression of emotion, detailed description of recalled events) versus just a rote and relatively brief response. One example of the deep engagement some participants had with the journal is exemplified in responses to a prompt asking each young woman to write a letter to her future self. Those who met the characteristics of deep engagement tended to write specific and emotional letters. The following are excerpts from two participant letters: 
Journal Prototype for Pregnant and Parenting Adolescents 20

Dear future me, keep up the good work finish school. Give your son a life you never had. Find a great guy and get married. Be successful in your doctor career. Make your dreams come true. I plan on graduating from high school and college. (age 15, parenting)

But the important thing is never stop going to school. Get that education for you and your child. Go to college and become somebody. Your child will follow in your footsteps! You don’t want their footsteps to be bad and lead him to failure. (age 18, parenting) None of the sections in the final journal collected insert was especially popular. Overall, response to the journal was lower in Part 2 compared to Part 1. As in Part 1, in journals that were sparsely used, the free response “What's On Your Mind?” sections elicited at least brief responses and was the best used section. It was difficult to assess whether the drop in engagement is a result of a) differences in journal content, b) a difference in the presentation of the content or c) or general fatigue with the journaling. For Part 3, journals included mostly average or brief, with no full or enthusiastic responses. In terms of the quality of engagement, two journals revealed demonstrated self-reflection, 3 had some indication of reflection, and 4 had rote responses. The best used sections of the returned journals included a prompt to write a letter of a future self, a prompt to reflect on their favorite person, and a prompt to list what they did over the past week.

Timing of the Implementation In our debriefing conversations, the ETAP staff explained that they found the timing of the journal shipments and return dates to be an impediment to journal use for participants. The timeframe for distribution and collection of inserts was shorter than expected due to logistical issues with our funding source, and ETAP staff felt that participants sometimes did not have new inserts in their possession long enough to use them to 
Journal Prototype for Pregnant and Parenting Adolescents 21

their fullest extent. In addition, the staff suggested starting the journal program while school is still in session rather than in the summer to promote more engagement with the journal, as many of their clients took vacations or had less predictable schedules in the summer months, which made coordination of the program more difficult than they anticipated.

\section{LESSONS LEARNED}

We identified various factors that contributed to the success and barriers of the implementation of a journaling program for pregnant and parenting adolescents. Drawing on literature suggesting the importance of program evaluation ( e.g., de Meij et al. 2013; Fixsen et al. 2005), the main strength of this study is that we used multiple methods of data collection and analysis to conduct a robust formative evaluation of this initial phase of the program (Jolley, 2014). The results of this evaluation can assist not only the research team as we pursue future phases of the project, but also practitioners interested in testing similar programs (Stetler et al. 2006).

Based on this implementation and evaluation of a journal prototype for pregnant and parenting adolescents, the project team developed a set of recommendations for refining the content of the journal and revising the design of the of journal implementation program. These recommendations reflect the results of our data analysis from multiple sources, including the survey, journal content and facilitator worksheets, and debriefing with ETAP staff.

\section{Suggestions for Refining Journal Content}

Based on our analysis, future versions of the journal should continue to include a combination of space for free-writing ("What's on your mind?”) as well as guided activities. The sections for free writing were valuable for providing participants with an opportunity to express a wide range of emotions and experiences. Although some of the structured sections were more 
Journal Prototype for Pregnant and Parenting Adolescents 22

widely used than others, the guided activities provided the delivery of content specific to PPASS priorities while also offering the potential for agency representatives and supportive others, such as the FSSs, to use these journal sections as conversation starters. The research team also recommends that future versions of the journal offer greater opportunities for customization tailored to the specific needs of users, including separate journals designed for pregnant versus parenting participants. Upon reflection at the end of the study, ETAP staff felt that many users who were pregnant at the time of the Part 1 distribution would have found the journal more useful and relevant if more of the structured content had been geared to pregnancy and prenatal care. Finally, the team recommends that journal modules also be designed for important support sources for each participant (such as their parent, grandparent, romantic partner). Based on the trend of participants' sharing their journals with others, it seems that interpersonal networks could play a key role in the lives of pregnant and parenting adolescents. Developing and implementing a journal prototype for the supportive others identified by the adolescents could serve to bolster and encourage the role of these relationships. In light of these suggestions, the team plans to redesign the journal to include pregnant and parenting versions, as well as a support person module, which will be tested in a future study.

\section{Suggestions for Improving Program Design}

The team also plans to refine the journaling program in a subsequent phase to reduce the burden on partner agencies and maximize participation by pregnant and parenting adolescents. One important improvement is to rework the timing of the implementation in order to accommodate partner agencies’ work practices and reduce participant attrition over time. A specific change suggested by ETAP was to implement the journal program during the academic year so that summer vacation schedules do not disrupt the process. In addition, our partner 
Journal Prototype for Pregnant and Parenting Adolescents 23

agency in this study typically had FSSs meet monthly with participants, and the journal was designed for new inserts to be distributed twice a month. Although the FSSs agreed to this additional workload prior to the implementation, they agreed that future programs should work within existing appointment structures to eliminate this burden. In the case of the current implementation, providing and collecting one journal a month would have reduced the burden on participants to complete their journals and the burden on facilitators and educators to collect the journals. Such a change could also reduce the rush for partner agencies to get materials returned to the project team on time. While our program provided valuable opportunities for pregnant and parenting adolescents to express their experiences, future research should assess the redesigned journals to explore whether perceptions of usefulness and trends in completion improve. Despite our informative findings, future research should also examine in greater detail factors associated with seamless integration of journaling into other contexts than what was studied in the present project. Such data will enable a better understanding of generalizability and best strategies that work for providers who care for pregnant and parenting adolescents.

\section{CONCLUSION}

Future implementation of the journal program that incorporates the recommendations drawn from this analysis could potentially provide participants with more relevant information, promote more prolonged engagement with the journal by pregnant and parenting adolescents, and decrease any inconvenience for partner agencies.

\section{ACKNOWLEDGEMENTS}

We would like to acknowledge and thank the following individuals for their significant contributions to this project: Michelle Howell, ETAP, for coordinating the project efforts of the ETAP team. Kenisha Harris, Michelle Hughes, Randi Huizenga, Cynthia Singleton, and 
Elizabeth Volkoff, family support specialists at ETAP for recruiting pregnant and parenting teens and supporting their journaling efforts. Michelle Derr, The Polis Center, for logistics planning and execution and serving as liaison with ETAP. Jennifer Wright, The Polis Center, for data entry and visualization.

\section{FUNDING SOURCE}

This project was funded through a partnership with the Indiana State Department of Health’s Pregnancy Assistance Fund Program: Support for Pregnant and Parenting Teens and Women. This program is sponsored by the Department of Health and Human Services, Office of Adolescent Health. ISDH did not play a role in study design; in the collection, analysis and interpretation of data; in the writing of the report; and in the decision to submit the article for publication.

\section{REFERENCES}

Azoulay, A, \& Kapferer, J.N. (2003). Do brand scales really measure brand personality? Brand Management, 11, 143-155.

Atkinson L.D., \& Peden-McAlpine C.J. (2013 online). Advancing adolescent maternal development: A grounded theory. Journal of Pediatric Nursing, in press.

Baikie, K. A. \& Wilhelm, K. (2005). Emotional and physical health benefits of expressive writing. Advances in Psychiatric Treatment, 11, 338-346.

Blake, T.K. (2005). Journaling: An active learning technique. International Journal of Nursing Education Scholarship, 2, 1-13.

Busum K.V., \& Mattke S. (2013). Financial incentives: Only one piece of the workplace 
Journal Prototype for Pregnant and Parenting Adolescents 25

wellness puzzle comment on "corporate wellness programs: implementation challenges in the modern American workplace”. International Journal of Health Policy and Management, 16, 311-2.

De Meij J.S., van der Wal, M.F., van Mechelen W., \& Chinapaw, M.J. (2013). A mixed methods process evaluation of the implementiaotn of JUMP-in, a multilevel school-based intervention aimed at physical activity promotion. Health Promotion Practice, 14, 77790.

Doniger, A.S., Adams, E., Utter, C. A., \& Riley, J.S. (2001). Impact evaluation of the "Not Me, Not Now" abstinence-oriented, adolescent pregnancy prevention communications program. Journal of Health Communication, 6, 45-60.

Fixsen D.L., Naoom S.F., Blasé K.A., Friedman R.M., \& Wallace F. (2005). Implementation Research: A synthesis of the literature. Tampa: University of South Florida.

Greenlahalgh T., Robert G., Macfarlane F., Bate P., \& Kyriakidou O. (2004). Diffusion of innovations in service organizations: Systematic review and recommendations. Milbank Quarterly, 82, 581-629.

Hamilton, B.E. and Ventura, S.J. (2012). Birth rates for U.S. teenagers reach historic lows for all age and ethnic groups. NCHS Data Brief. No. 89, Hyattsville, MD: National Center for Health Statistics. 2012. Retrieved May 17, 2012, from http://www.cdc.gov/nchs/data/databriefs/db89.htm

Hodgkinson, S., Beers L., Southammakosane C., \& Lewin A. (2013). Addressing the mental health needs of pregnant and parenting adolescents. Pediatrics, 133, 114-122.

Jolley, G. (2014). Evaluating complex community-based health promotion: Addressing the challenges. Evaluation and Program Planning Apr 1; 45C:71-81 [Epub ahead of print]. 
Journal Prototype for Pregnant and Parenting Adolescents 26

Keeling, M. L. \& Bermudez, M. (2006). Externalizing problems through art and writing:

Experience of process and helpfulness. Journal of Marital and Family Therapy. 32, 405419.

Kitson A., Harvey G., \& McCormack B. (1998). Enabling the implementation of evidence based practice: A conceptual framework. Quality in Health Care, 7(3), 149-158.

Lepore, S. J. \& Smyth, J. M., Eds. (2002). The Writing Cure. United Books, Baltimore, MD.

Martin, J. A., Hamilton, B. E., Ventura, S. J., Menacker, F., \& Kirmeyer, S. (2006). Births: Final Data for 2004. National Vital Statistics Reports, 55, 1-102.

Owen, W.F. (1984). Interpretive themes in relational communication. Quarterly Journal of Speech, 70, 274-287.

Pennebaker, J. W. \& Beall, S. K. (1986). Confronting a traumatic event: Toward an understanding of inhibition and disease. Journal of Abnormal Psychology, 95, 274-281.

Pennebaker, J.W. \& Seagal, J.D. (1999). Forming a story: The health benefits of narrative. J Clin Psychol 55; 1243-1254.

Perper, K., Peterson, K., \& Manlove, J. (2010). Diploma attainment among teen mothers. Child Trends, Fact Sheet Publication. Washington, DC.

Pinkleton, B.E., Austin, E.W., Cohen, M., Chen, Y., Fitzgerald, E. (2008). Effects of a peer-led media literacy curriculum on adolescents' knowledge and attitudes toward sexual behavior and media portrayals of sex. Health Communication,23, 462-472.

Roberto, A.J., Carlyle, K.E., Zimmerman, R. S.,Abner, E. L., Cupp, P. K., \& Hansen, G. L. (2008). The short-term effects of a computer-based pregnancy, STD, and HIV prevention program. Communication Quarterly,56, 29-48.

Roberto, A.J., Zimmerman, R.S., Carlyle, K. E., \& Abner, E. L. (2007). A computer-based 
approach to preventing pregnancy, STD, and HIV in rural adolescents. Journal of Health Communication, 12, 53-76.

Stetler C.B., Legro M.W., Wallace C.M., Bowman C., Guihan M., Hagedorn H., Kimmel B., Sharp N.D., \& Smith J.L. (2006). The role of formative evaluation in implementation research and the QUERI Experience. J Gen Intern Med; 21: S1-8.

The National Campaign to Prevent Teen and Unplanned Pregnancy (2010)Fast facts: Teen pregnancy in the United States. Retrieved from http://www.thenationalcampaign.org/resources/pdf/FastFacts_TeenPregnancyinUS.pdf Thomas, T.L., Owens, O.L., Friedman, D.B., Torres, M.E., \& Hébert, J.R. (2012). Written and spoken narratives about health and cancer decision making: A novel application of photovoice. Health Promotion Practice. DOI: 10.1177/1524839912465749

Tse, J., Nansel, T.R., Weaver, N.L., Williams, J., Botello-Harbaum, M. (In press). Implementation of a tailored kiosk-based injury prevention program in pediatric primary care. Health Promotion Practice.

van Nassau F., Singh A.S., Mechelen W., Paulussen T.G.W.M., Brug J., \& Chinapaw M.J.M. (2013). Exploring facilitating factors and barriers to the nationwide dissemination of a Dutch school-based obesity prevention program “DOiT”: a study protocol. BMC Public Health, 13:1201. 
Table 1

Pregnant and Parenting Adolescent Support Services (PPASS) Program Goals

PPASS Priority Areas

- Strengthen infrastructure to assist pregnant and parenting 15 to 19 year-olds

- Reduce subsequent pregnancies among 15 to 19 year-olds

- Decrease school drop-out rates among pregnant and parenting 15 to 19 year-olds

- Improve birth outcomes among pregnant and parenting 15 to 19 year-olds

Additional PPASS Priority Areas (Recommend but not Required)

- Increase awareness and use of services available to pregnant and parenting 15 to 19 yearolds

- Increase number of teens with knowledge of appropriate parenting-skills

- Increase number of teens who report access to early and adequate prenatal care and up-todate well child visits

- Increase support for pregnant and parenting 15 to 19 year-olds in interactions with the healthcare system

- Increase percent of teens who achieve appropriate weight gain during pregnancy

- Decrease percent of teens who smoke during pregnancy (and remain tobacco-free after pregnancy)

- Increase staff knowledge and skills in the implementation of evidence-based programs

- Increase involvement of teen fathers in programs that serve teen mothers

- Decrease barriers to care

- Increase inclusion of youth and community members in the development of programs

- Increase number of teens who enroll in secondary education

- Increase access to mental healthcare including substance abuse treatment programs

- Increase access to domestic violence support services

- Increase availability of and/or access to childcare 
Figure 1

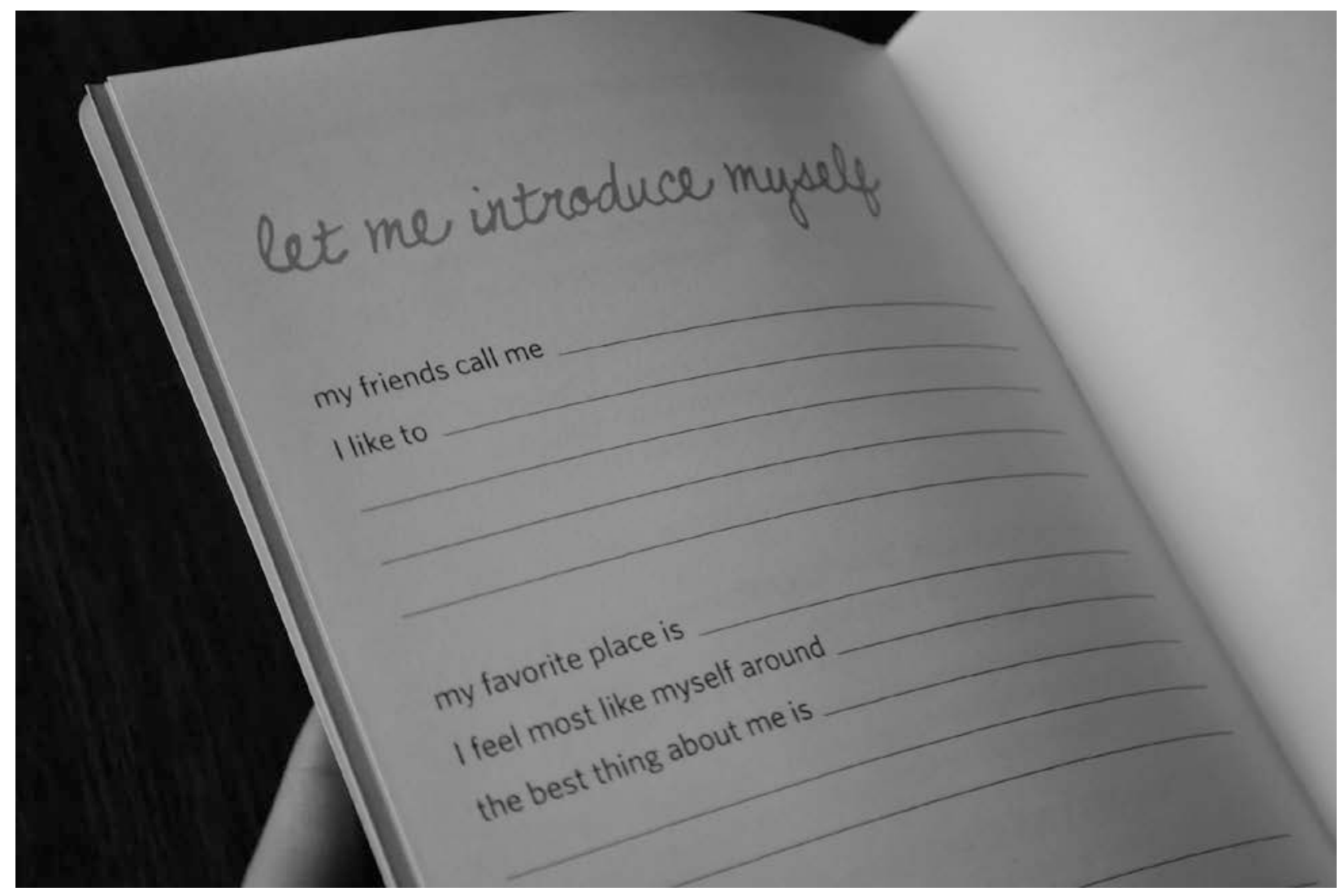

Figure 1: Sample page of the journal prototype developed for phase 2. 
Figure 2

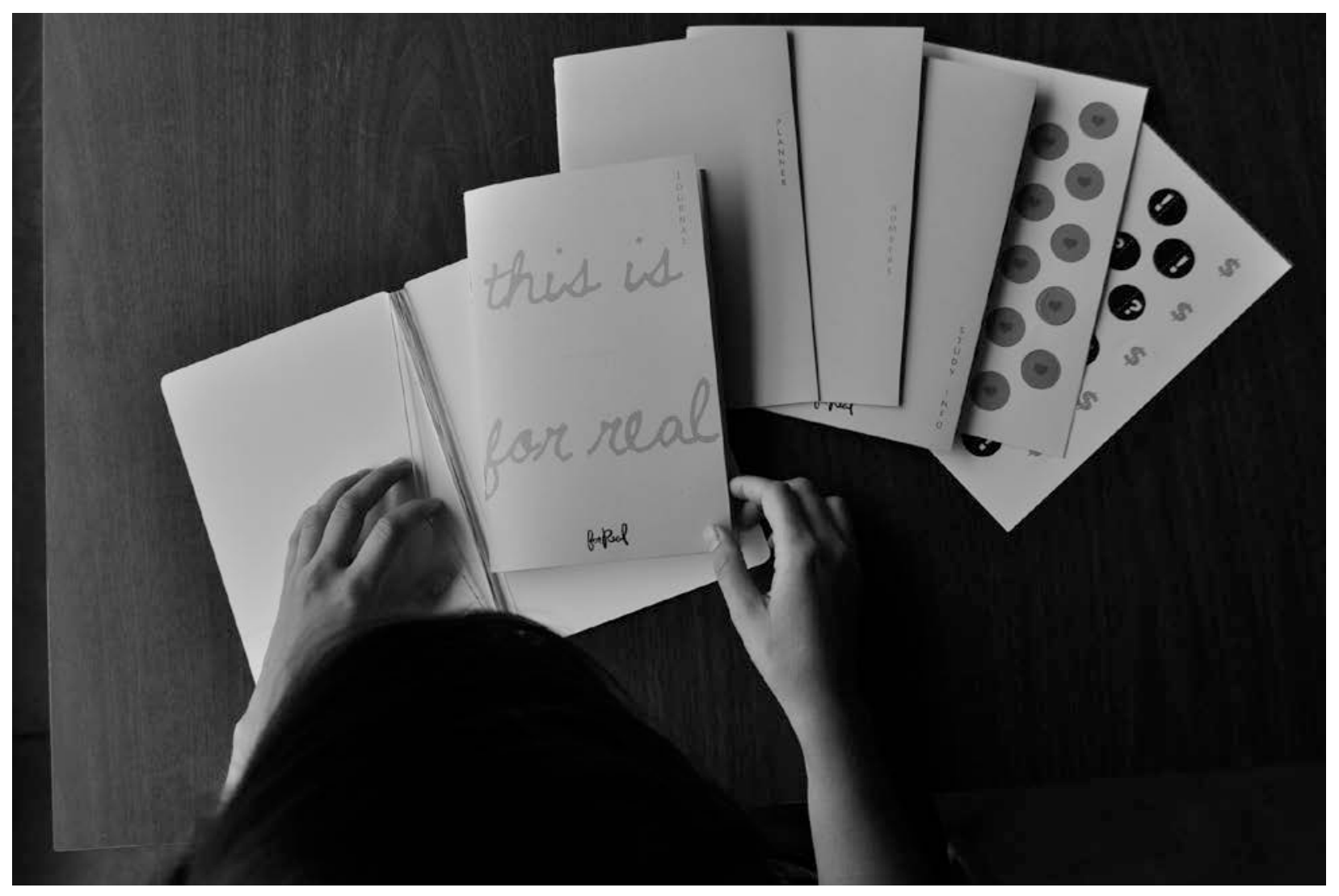

Figure 2: This image illustrates the modular nature of the journal. The banded pages allow for the easy insertion of new pages and updated calendars. 
Figure 3

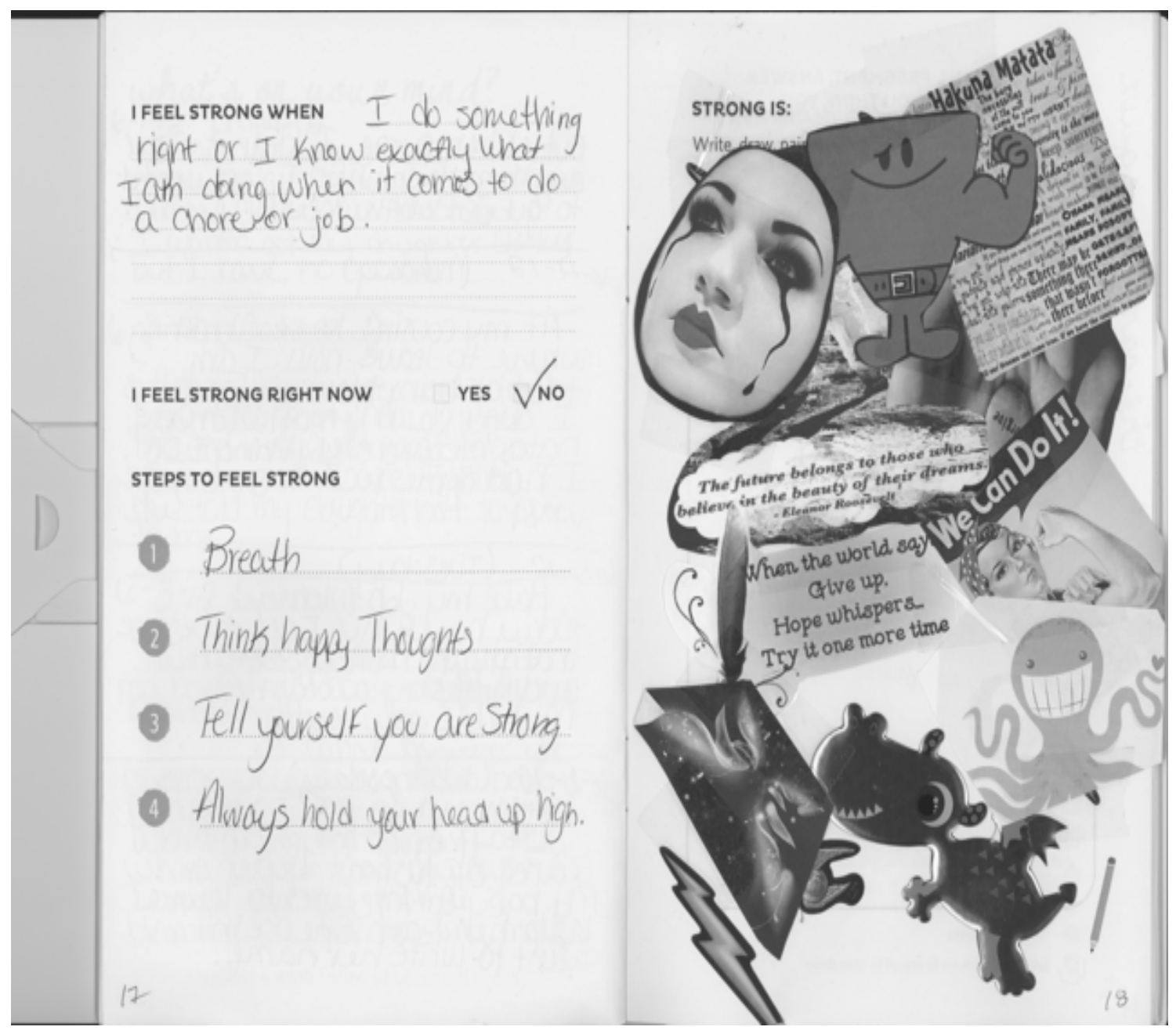

Figure 3: This image illustrates a completed “I Feel Strong When” section that suggests a deep level of engagement with the journal. 